\title{
Effects of AMP-activated protein kinase (AMPK) signaling and essential amino acids on mammalian target of rapamycin (mTOR) signaling and protein synthesis rates in mammary cells
}

\author{
J. A. D. R. N. Appuhamy, ${ }^{* 1,2}$ W. A. Nayananjalie, ${ }^{*}$ E. M. England, $\dagger$ D. E. Gerrard,† R. M. Akers, ${ }^{*}$ \\ and M. D. Hanigan* \\ ${ }^{*}$ Department of Dairy Science, and \\ †Department of Animal and Poultry Science, Virginia Polytechnic Institute and State University, Blacksburg 24061
}

\section{ABSTRACT}

Regulation of mammary protein synthesis potentially changes the relationships between AA supply and milk protein output represented in current nutrient requirement models. Glucose and AA regulate muscle protein synthesis via cellular signaling pathways involving mammalian target of rapamycin (mTOR) and AMPactivated protein kinase (AMPK). The objective of this study was to investigate the effects of essential AA (EAA) and acetate or glucose on mTOR and AMPK signaling pathways and milk protein synthesis rates. A bovine mammary epithelial cell line, MAC-T, was subjected to different media containing 0 or $3.5 \mathrm{mmol} / \mathrm{L}$ EAA concentrations with 0 or $5 \mathrm{mmol} / \mathrm{L}$ acetate or 0 or $17.5 \mathrm{mmol} / \mathrm{L}$ glucose in 2 separate $2 \times 2$ factorial studies. In a separate set of experiments, lactogenic bovine mammary tissue slices were subjected to the same treatments except that the low EAA treatment contained a low level of EAA $(0.18 \mathrm{mmol} / \mathrm{L})$. Supplementation of EAA enhanced phosphorylation of mTOR (Ser2448) and eukaryotic initiation factor 4E binding protein 1 (4EBP1, Thr37/46), and reduced phosphorylation of eukaryotic elongation factor 2 (eEF2, Thr56) in MAC-T cells. Concentration of ATP and phosphorylation of AMPK increased and decreased, respectively, in the presence of EAA in MAC-T cells. Acetate, EAA, or glucose numerically reduced AMPK phosphorylation by about $16 \%$ in mammary tissue slices. Provision of EAA increased phosphorylation of mTOR and 4EBP1, intracellular total EAA concentration, and casein synthesis rates in mammary tissue slices, irrespective of the presence of acetate or glucose in the medium. Phosphorylation of mTOR had a marginally negative association with AMPK phosphorylation, which was

Received June 26, 2013.

Accepted August 23, 2013.

${ }^{1}$ Corresponding author: jaappuhamy@ucdavis.edu

${ }^{2}$ Current affiliation: Department of Animal Science, University of California, Davis 95616. positively related to eEF2 phosphorylation. Casein synthesis rates were positively and more strongly linked to mTOR phosphorylation than the negative link between eEF2 phosphorylation and casein synthesis rates. A $100 \%$ increase in mTOR phosphorylation was associated with an increase in the casein synthesis rate of $0.74 \% \cdot \mathrm{h}^{-1}$, whereas a $100 \%$ increase in eEF2 phosphorylation was related to a decline in the casein synthesis rate of $0.33 \% \cdot \mathrm{h}^{-1}$. Although AMPK phosphorylation was responsive to cellular energy status and had a negative effect on mTOR-mediated signals in bovine mammary epithelial cells, its effect on milk protein synthesis rates appeared to be marginal compared with the mTOR-mediated regulation of milk protein synthesis by EAA.

Key words: AMP-activated protein kinase (AMPK), essential amino acid, casein synthesis, energy substrate

\section{INTRODUCTION}

Poor N utilization efficiency of dairy cows leads to significant $\mathrm{N}$ losses in urine and feces (Huhtanen and Hristov, 2009). This loss of N represents both an economic and environmental cost. Increasing urinary $\mathrm{N}$ excretion is indicative of greater catabolism of $\mathrm{AA}$ in the body, with splanchnic tissues being a major contributor. Splanchnic catabolism of AA is proportional to arterial AA concentrations, which are influenced by AA uptake by nonsplanchnic tissues, such as the lactating mammary gland. In contrast, AA uptake by mammary glands appears to be a function of arterial concentration, blood flow, and metabolic demand. Therefore, if AA supply to the animal remains constant while use for milk protein synthesis is increased, the increased demand for AA by mammary tissue will draw down arterial AA concentrations, leading to reduced AA catabolism by the splanchnic tissues (Hanigan et al., 1998). Moreover, AA are not only precursors for protein synthesis but they also play a significant regulatory role (Kimball and Jefferson, 2006). Protein synthesis regulation potentially violates the assumption of fixed 
efficiencies of absorbed AA conversion to milk protein in current nutrient requirement models. Understanding milk protein synthesis regulation is therefore important for improving protein and AA requirement models.

We previously (Appuhamy et al., 2011, 2012) demonstrated that essential AA (EAA) enhanced milk protein synthesis rates by signaling via the mammalian target of rapamycin (mTOR) pathway. Phosphorylation of mTOR at Ser2448 is indicative of mTOR pathway activity in bovine mammary epithelial cells (Appuhamy et al., 2011). Phosphorylated, and thus activated, mTOR in turn regulates phosphorylation of eukaryotic initiation factor $4 \mathrm{E}$ binding protein (4EBP1) and eukaryotic elongation factor 2 (eEF2), which are rate limiting to the initiation and elongation steps of milk protein synthesis, respectively (Appuhamy et al., 2011).

Increased availability of glucose, and thereby improved cellular energy status, has also been shown to stimulate protein synthesis in muscle cells (Bolster et al., 2002; Jeyapalan et al., 2007; Deshmukh et al., 2008). These signals involve AMP-activated protein kinase (AMPK), which is able to sense cellular energy status. Cellular energy stress activates AMPK by phosphorylating it. Once activated, AMPK inhibits ATPconsuming processes, such as protein synthesis, while enhancing ATP-producing processes, such as fatty acid oxidation and glucose uptake (Mukherjee et al., 2008). One of the targets inhibited by activated AMPK is mTOR (Kudchodkar et al., 2007).

Consistent with the fact that milk protein synthesis is an energy-consuming process (Lobley, 1990; Hanigan and Baldwin, 1994), Burgos et al. (2013) showed that activation of AMPK repressed global protein synthesis via inhibition of mTOR signals in bovine mammary epithelial cells. These authors activated AMPK with 2-deoxyglucose. However, examining the effect of the energy substrates acetate and glucose on AMPK and, specifically, milk protein synthesis would be more beneficial and relevant from a nutritional standpoint. Moreover, Safayi and Nielsen (2013) recently suggested that $\mathrm{N}$ balance differences can lead to differential glucose and acetate effects on milk protein synthesis, indicating the importance of testing the acetate and glucose effects compared with AA availability. Therefore, the objectives of the present study were to investigate the effects of glucose, acetate, and EAA concentrations on AMPK, mTOR, 4EBP1, eEF2, and casein synthesis rates, and to explore relationships among the signaling proteins and casein synthesis rates in bovine mammary epithelial cells.

\section{MATERIALS AND METHODS}

The Animal Care and Use Committee of Virginia Tech approved all procedures. This study was con- ducted according to the Federation of Animal Science Societies' Guide for the Care and Use of Agricultural Animals in Research and Teaching (FASS, 2010).

\section{Cells and Tissues}

Two separate sets of experiments were conducted using an immortalized bovine mammary epithelial cell line, MAC-T (Huynh et al., 1991), and mammary tissue slices from lactating cows. Cells were seeded on 6-well plates at a cell density of $5,625 \mathrm{cells} / \mathrm{cm}^{2}$ and cultured at $37^{\circ} \mathrm{C}$ in $5 \% \mathrm{CO}_{2}$ to about $90 \%$ confluency. Cells were grown in Dulbecco's modified Eagle medium/F12 (DMEM/F12; Invitrogen, Carlsbad, CA) supplemented with $8 \%$ (vol/vol) fetal bovine serum and containing $3.51 \mathrm{mg}$ of D-glucose, $100 \mathrm{U}$ of penicillin, $100 \mu \mathrm{g}$ of streptomycin, and $0.25 \mu \mathrm{g}$ of amphotericin B (HyClone Laboratories Inc., Logan, UT) per milliliter. Four multiparous lactating Holstein cows were screened for mastitis, deprived of food for $12 \mathrm{~h}$, and slaughtered in accordance with the US Department of Agriculture Food Safety and Inspection Services regulations. Mammary tissue slices $(130 \pm 30 \mathrm{mg})$ were prepared within 30 min of slaughter from a clean rear quarter using a Stadie-Riggs handheld microtome and placed in $25-\mathrm{mL}$ Erlenmeyer flasks containing $4 \mathrm{~mL}$ of treatment medium, as described previously (Appuhamy et al., 2011).

\section{Treatments and Experimental Design}

MAC-T Cell Experiments. The MAC-T cells were serum starved overnight and treated with 2 levels of EAA and 2 levels of sodium acetate in a $2 \times 2$ factorial arrangement of treatments. Essential AA levels were those of complete DMEM/F12 (3.5 mmol/L) or DMEM/F12 devoid of EAA $(0 \mathrm{mmol} / \mathrm{L})$. Sodium acetate levels were 0 or $5 \mathrm{mM}$ (in the absence of glucose). In a separate experiment, the cells were treated with the same EAA levels and 2 D-glucose levels: 0 and $17.5 \mathrm{mmol} / \mathrm{L}$ (in the absence of acetate) again in a $2 \times 2$ factorial arrangement of treatments. The 17.5 $\mathrm{mmol} / \mathrm{L}$ level is the normal glucose level in complete DMEM/F12. The high levels of acetate, glucose, and EAA were more than 3 -fold greater than normal blood concentrations in dairy cows (Purdie et al., 2008; Rius et al., 2010). The basal media to which EAA, glucose, or acetate was added were completely deprived of EAA, glucose and acetate, and contained $3.7 \mathrm{mmol}$ of nonEAA (standard DMEM/F12 concentrations), $0.1 \mathrm{mg}$ of insulin, $0.02 \mathrm{mmol}$ of phenol red, $0.50 \mathrm{mmol}$ of sodium pyruvate, and $14.0 \mathrm{mmol}$ of sodium bicarbonate per L. All the treatment media were free of serum and adjusted to a $\mathrm{pH}$ of 7.4. 
After a 1-h incubation in treatment media, culture plates were placed on ice and $2 \mathrm{~mL} /$ well of stop buffer (sterile PBS containing $1 \mathrm{~m} M \mathrm{NaF}$ and $10 \mu M \mathrm{Na}_{3} \mathrm{VO}_{4}$ ) was added. Cells were lysed by scraping cells into ice-cold lysis buffer containing 1\% (vol/vol) protease and phosphatase inhibitor cocktail (ThermoScientific, Rockford, IL). Cell lysates from 6 wells were combined and each treatment was repeated 4 times on 4 different days. Using a separate experimental replicate (n $=3$ ), ATP content in MAC-T cells was measured as described by Manfredi et al. (2002). Briefly, after treatment medium had been removed, $250 \mu \mathrm{L}$ of $0.5 \mathrm{~mol} / \mathrm{L}$ perchloric acid was added into each well and the cells were scraped. Cell lysates were centrifuged $(23,000 \times g$ for $10 \mathrm{~min}$ at $4^{\circ} \mathrm{C}$ ) and the supernatant was neutralized by adding $2 \mathrm{~mol} / \mathrm{L}$ potassium hydroxide (4:1, vol/vol). After another round of centrifugation $(23,000 \times g$ for 10 min at $4^{\circ} \mathrm{C}$ ), the supernatant was injected into an HP Agilent 1100 HPLC system (Agilent Technologies, Santa Clara, CA) and separated with 2 mobile phases using a Phenomenex Kinetex 2.6- $\mu$ m C18 column (4.6 $\times 50 \mathrm{~mm}$; Phenomenex, Torrance, CA). Mobile phase A consisted of $5 \mathrm{mM}$ tetrabutylammonium hydrogen sulfate, $100 \mathrm{mM} \mathrm{KH_{2 }} \mathrm{PO}_{4}$ (pH 6.0), and $2.5 \%$ acetonitrile. Mobile phase $\mathrm{B}$ was the same except it contained $25 \%$ acetonitrile ( $\mathrm{pH} 5.5$; Bernocchi et al., 1994; Williams et al., 2008). Nucleotide concentrations were detected with a UV/visible spectrophotometer at $260 \mathrm{~nm}$ and quantified using a standard curve of commercially available ATP.

Mammary Tissue Slice Experiments. The mammary tissue slice experimental design and treatments were the same as for MAC-T cells, except that an altered level of EAA (5\% of regular DMEM/F12 concentrations) for the $-\mathrm{EAA}$ treatments was chosen to measure fractional protein synthesis rates (FSR) using ${ }^{2} \mathrm{H}_{5}$-Phe as previously described (Appuhamy et al., 2011). Duplicate mammary tissue slices from each cow were randomly assigned to treatment media in the 25-mL Erlenmeyer flasks, purged with a 95:5 mix of $\mathrm{O}_{2}: \mathrm{CO}_{2}$ for $20 \mathrm{~s}$, sealed with rubber stoppers, and placed in a shaking (60 oscillation/h) water bath at $37^{\circ} \mathrm{C}$ (time $=0)$. Flasks were opened at $75 \mathrm{~min}$ to add ${ }^{2} \mathrm{H}_{5}$-Phe, purged with the gas mix again, and incubated in the shaking water bath for another $45 \mathrm{~min}$. The medium maintained $\mathrm{pH}$ throughout the incubation, as indicated by the phenol red. Tissue remained viable during the incubation as evidenced by ${ }^{2} \mathrm{H}_{5}$-Phe incorporation into mammary protein over the last $45 \mathrm{~min}$ of the incubation. Label incorporation rates were found to be linear for $8 \mathrm{~h}$ (unpublished data), consistent with the findings of others (Bauman et al., 1973; Dimenna and Emery, 1980; O'Quinn et al., 2002), where various metabolic and synthetic processes remained linear for at least $2 \mathrm{~h}$ when mammary tissue was incubated in this manner.

Following incubation, tissue slices were retrieved and homogenized as previously described (Appuhamy et al., 2011). Aliquots of cell homogenate supernatant were mixed with equal volumes of $2 \times$ Laemmli buffer, incubated at $80^{\circ} \mathrm{C}$ for $8 \mathrm{~min}$, and stored at $-80^{\circ} \mathrm{C}$ until immunoblot analyses. Casein-enriched protein precipitates were obtained by adjustment of $\mathrm{pH}$ to 4.6. The effectiveness of this enrichment procedure was determined from 6 random mammary tissue slices by Coomassie blue staining after electrophoretic separation on $12 \%$ SDS-PAGE gel. Casein bands were determined by visual comparison with purified bovine casein (SigmaAldrich, St. Louis, MO). Protein band intensities were measured with an Odyssey Infrared Imaging System (Li-Cor Biosciences, Lincoln, NE). Casein was found to represent $49 \pm 10 \%$ of the total stained protein in a lane (results not shown). This indicates that the FSR results in the present study can reasonably be related to milk protein synthesis rates, although other proteins were present in the precipitate. Protein-bound $\left[\boldsymbol{E}_{\boldsymbol{P B}}\right.$ (\%)] and intracellular $\left[\boldsymbol{E}_{I C}(\%)\right]^{2} \mathrm{H}_{5}$-Phe enrichments, and intracellular EAA concentrations were determined as previously described (Appuhamy et al., 2011).

Random mammary tissue samples from each cow were obtained simultaneously with the tissues slices and used to prepare microscopy slides, which were stained with hematoxylin and eosin (Sigma) as described previously (Daniels et al., 2009). Stained images of mammary tissue were captured with a top-mounted digital microscope camera (Olympus DP10, Opelco, Dulles, VA) under $40 \times$ magnification. Four images, each representing mammary tissues harvested from each of 4 cows, are presented in Figure 1. As evidenced by Figure 1, the harvested mammary tissue slices contained a high proportion of epithelial cells. Therefore, the observed cellular signaling effects can be reasonably related to milk protein synthesis.

\section{Protein Immunoblot Analysis}

Cell lysate aliquots (20 $\mu \mathrm{g}$ of protein) were subjected to protein immunoblot analyses as previously described (Escobar et al., 2006). Electrophoretically separated proteins were transferred to polyvinylidene fluoride (PVDF) membranes (Millipore, Billerica, MA) and incubated with antibodies (Cell Signaling Technology, Danvers, MA) recognizing phosphorylated forms of AMPK (Thr172), mTOR (Ser2448), 4EBP1 (Thr37/46), and eEF2 (Thr56). Visualized immunoblots were then stripped and reprobed with the corresponding total antibodies (Cell Signaling Technology). 

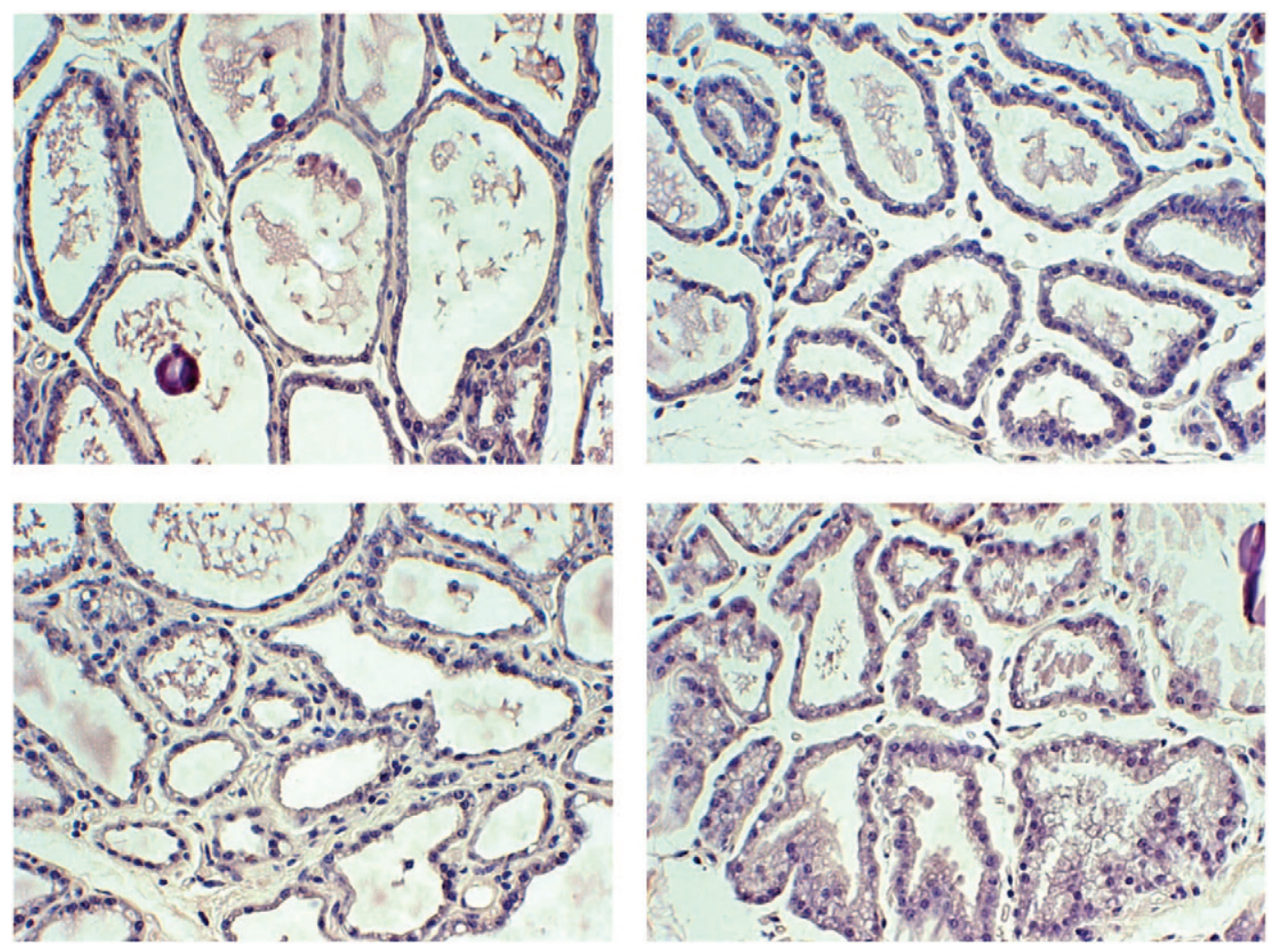

Figure 1. Representative images of mammary tissues (stained with hematoxylin and eosin) from 4 lactating cows at $20 \times$ magnification. Color version available in the online PDF.

Because we were unable to detect total 4EBP1, the $4 \mathrm{EBP} 1$ phosphorylation was calculated relative to the

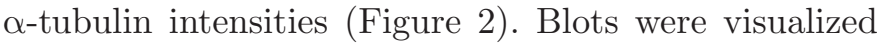
using enhanced chemiluminescence (ECL Plus, GE Healthcare, Piscataway, NJ) and digitized and integrated using Un-Scan-It (Silk Scientific Inc., Orem, UT). Phosphorylation state was calculated as the ratio of phosphorylated form to the total.

\section{Fractional Rate of Protein Synthesis}

Casein-rich precipitates from mammary tissue slices were hydrolyzed with $6 \mathrm{~N} \mathrm{HCl}$ in $0.1 \%$ phenol at $110^{\circ} \mathrm{C}$ for $20 \mathrm{~h}$. The hydrolysate and the supernatant collected from the precipitation were desalted by ion exchange chromatography, and converted to $\mathrm{N}$-(tert-butyldimethyl) AA derivatives as described previously (Bequette et al., 1999). The $E_{P B}$ and $E_{I C}$ were quantified by GC-MS (GC-MS Trace GC Ultra-DSQII, Thermo Electron Corp., Waltham, MA) using selected ion monitoring to determine the ratio of the 239 and $234 \mathrm{~m} / z$ ions. Calibration curves were generated to determine $E_{P B}$ and $E_{I C}$ as previously described (Bequette et al., 2002). The FSR were calculated as

$$
F S R=\frac{E_{P B} \times 100}{E_{I C} \times t},
$$

where $t$ is the incubation time of mammary tissue slices in media containing ${ }^{2} \mathrm{H}_{5}$-Phe $(0.75 \mathrm{~h})$ and the units of FSR are $\% \cdot h^{-1}$.

\section{Statistical Analysis}

The main effects of acetate or glucose and EAA and their interaction on phosphorylation state of signaling proteins (in both MAC-T cells and mammary tissue slices), ATP content (only in MAC-T cells), and FSR and intracellular EAA concentrations (only in mammary tissue slices) were analyzed using the following statistical model with the MIXED procedure of SAS (version 9.2; SAS Institute Inc., Cary, NC):

$$
\mathrm{Y}_{\mathrm{ijk}}=\mu+\mathrm{EAA}_{\mathrm{i}}+\mathrm{ES}_{\mathrm{j}}+(\mathrm{EAA} \times \mathrm{ES})_{\mathrm{ij}}+\mathrm{e}_{\mathrm{ijk}},
$$

where $\mathrm{Y}_{\mathrm{ijk}}=$ phosphorylation state, ATP content, FSR, or intracellular EAA concentration; $\mu=$ mean phosphorylation state, ATP content, FSR, or intracellular 


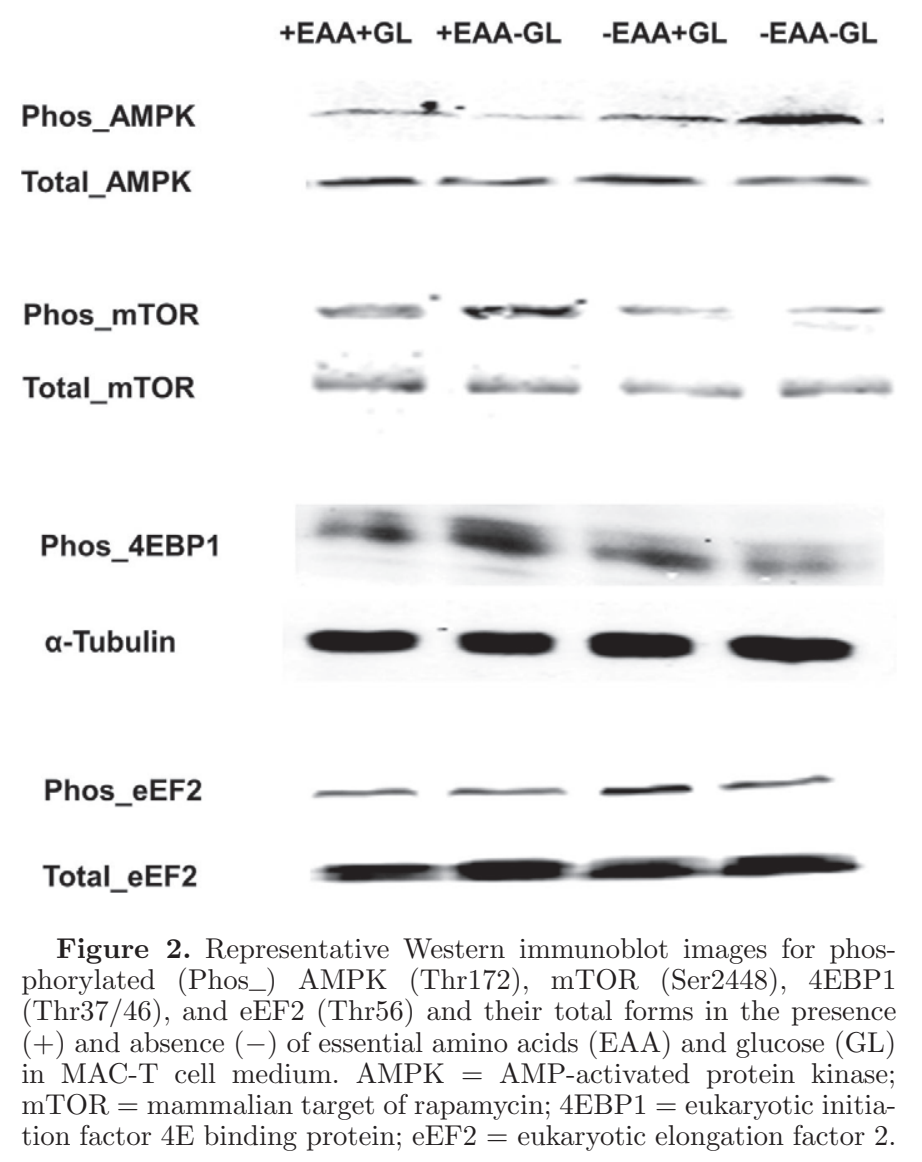

EAA concentration; $\mathrm{EAA}_{\mathrm{i}}=$ fixed effect of EAA in medium; $\mathrm{ES}_{\mathrm{j}}=$ fixed effect of energy substrate (acetate or glucose $)$ in medium; $(\mathrm{EAA} \times \mathrm{ES})_{\mathrm{ij}}=$ fixed interactive effect between EAA and energy substrate; and $\mathrm{e}_{\mathrm{ijk}}=$ random error. Phosphorylation state was normalized to the average value (across replicates) of negative control treatments. Meaningful relationships among phosphorylation state of the signaling proteins, intracellular total EAA concentration, and FSR in mammary tissue slices were quantified separately with simple linear regression models and multiple linear regression models using the REG procedure of SAS. Mean response variable values (within treatment within each cow) across both acetateEAA and glucose-EAA experiments were used in the regression analyses. The normalized phosphorylation ratios were used for corresponding regression analyses. Hence, a 1-fold (or 100\%) increase in phosphorylation of a signaling protein is equivalent to the amount of phosphorylation measured in the absence of EAA and the energy substrates.

\section{RESULTS}

\section{MAC-T Cells}

Acetate-EAA Experiment. Addition of essential amino acids $(+\mathrm{EAA})$ reduced $(P=0.03)$ AMPK phosphorylation by $30 \%$, with or without acetate in the medium (Table 1). Consistently, EAA supplementation increased $(P=0.03)$ ATP content in MAC-T cells by $38 \%$ (60.6 vs. $83.8 \mu \mathrm{mol} / \mathrm{mg}$ of protein) irrespective of the presence of acetate. Only EAA affected mTOR and eEF2 phosphorylation. Addition of EAA increased mTOR phosphorylation $(P<0.01)$ and decreased eEF2 phosphorylation $(P=0.02)$, regardless of acetate in the medium. Acetate did not have an individual or an interactive effect with EAA on the phosphorylation state of the signaling proteins or ATP content in MAC$\mathrm{T}$ cells.

Table 1. Effects (least squares means) of essential AA (EAA) and acetate (AC; top half of table) or EAA and glucose (GL; bottom half of table) on signaling protein phosphorylation and cellular ATP concentrations in MAC-T cells

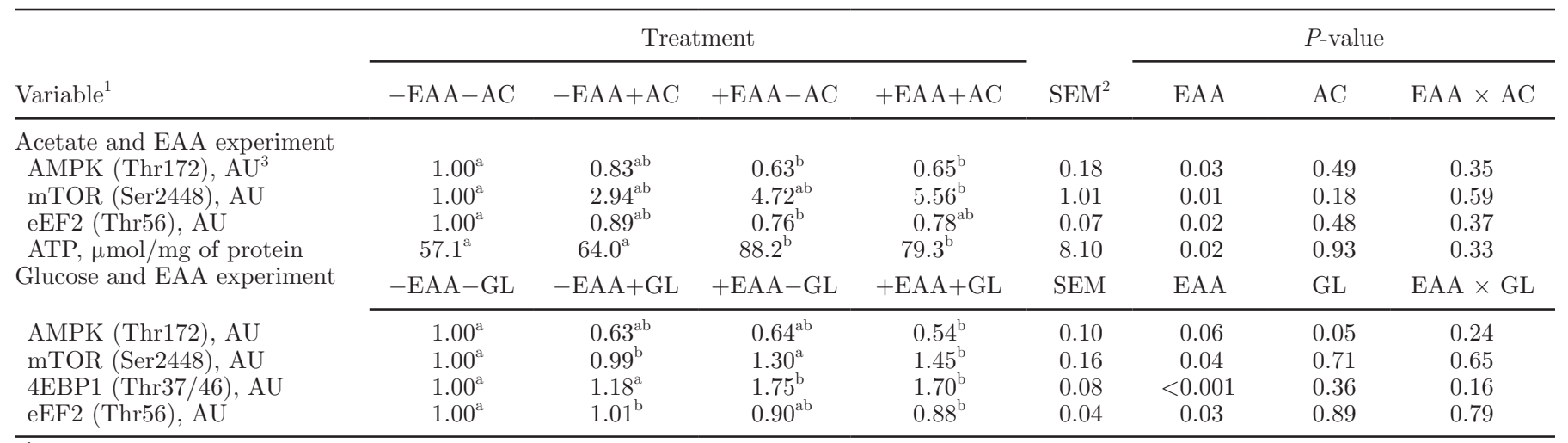

${ }^{\mathrm{a}, \mathrm{b}}$ Means in a row with superscripts without a common letter differ, $P<0.10$.

${ }^{1} \mathrm{AMPK}=\mathrm{AMP}$-activated protein kinase; $\mathrm{mTOR}=$ mammalian target of rapamycin; eEF2 = eukaryotic elongation factor $2 ; 4 \mathrm{EBP} 1=$ eukaryotic initiation factor $4 \mathrm{E}$ binding protein.

${ }^{2}$ Pooled standard error of the means.

${ }^{3}$ Normalized phosphorylation ratios (phosphorylated protein:total protein) expressed in arbitrary units (AU). 
Table 2. Effects (least squares means) of essential AA (EAA) and acetate (AC; top half of table) or EAA and glucose (GL; bottom half of table) on signaling protein phosphorylation, total intracellular EAA concentrations (ICEAA), and fractional synthesis rates of casein (FSR) in bovine mammary tissue slices

\begin{tabular}{|c|c|c|c|c|c|c|c|c|}
\hline Variable $^{1}$ & \multicolumn{4}{|c|}{ Treatment } & $\mathrm{SEM}^{2}$ & \multicolumn{3}{|c|}{$P$-value } \\
\hline \multicolumn{9}{|l|}{ Acetate and EAA experiment } \\
\hline mTOR (Ser2448), AU & $1.00^{\mathrm{ab}}$ & $0.79^{\mathrm{a}}$ & $1.64^{\mathrm{b}}$ & $1.72^{\mathrm{b}}$ & 0.30 & 0.01 & 0.81 & 0.58 \\
\hline 4EBP1 (Thr37/46), AU & $1.00^{\mathrm{a}}$ & $1.05^{\mathrm{a}}$ & $2.1^{\mathrm{b}}$ & $2.01^{\mathrm{b}}$ & 0.23 & $<0.001$ & 0.87 & 0.86 \\
\hline eEF2 (Thr56), AU & 1.00 & 1.57 & 1.05 & 0.82 & 0.37 & 0.22 & 0.54 & 0.16 \\
\hline Glucose and EAA experiment & $-\mathrm{EAA}-\mathrm{GL}$ & $-\mathrm{EAA}+\mathrm{GL}$ & $+\mathrm{EAA}-\mathrm{GL}$ & $+\mathrm{EAA}+\mathrm{GL}$ & SEM & EAA & GL & $\mathrm{EAA} \times \mathrm{GL}$ \\
\hline AMPK (Thr172), AU & 1.00 & 0.77 & 0.85 & 0.76 & 0.09 & 0.44 & 0.10 & 0.48 \\
\hline mTOR (Ser2448), AU & $1.00^{\mathrm{a}}$ & $1.21^{\mathrm{ab}}$ & $1.88^{\mathrm{b}}$ & $1.53^{\mathrm{ab}}$ & 0.24 & 0.04 & 0.79 & 0.27 \\
\hline 4EBP1 (Thr37/46), AU & $1.00^{\mathrm{a}}$ & $1.25^{\mathrm{ab}}$ & $2.57^{\mathrm{b}}$ & $2.14^{\mathrm{b}}$ & 0.76 & 0.01 & 0.82 & 0.47 \\
\hline eEF2 (Thr56), AU & 1.00 & 1.33 & 1.02 & 0.87 & 0.28 & 0.21 & 0.57 & 0.16 \\
\hline ICEAA, $\mathrm{mol} / \mathrm{L}$ & $0.30^{\mathrm{a}}$ & $0.31^{\mathrm{a}}$ & $1.43^{\mathrm{b}}$ & $1.13^{\mathrm{b}}$ & 0.15 & $<0.001$ & 0.34 & 0.32 \\
\hline
\end{tabular}

${ }_{\mathrm{a}, \mathrm{b}}$ Means in a row with superscripts without a common letter differ, $P<0.10$.

${ }^{1} \mathrm{AMPK}=\mathrm{AMP}$-activated protein kinase; $\mathrm{mTOR}=$ mammalian target of rapamycin; 4EBP1 = eukaryotic initiation factor $4 \mathrm{E}$ binding protein; eEF2 = eukaryotic elongation factor 2 .

${ }^{2}$ Pooled standard error of the means.

${ }^{3}$ Normalized phosphorylation ratios (phosphorylated protein:total protein) expressed in arbitrary units (AU).

${ }^{4}$ Sum of the intracellular concentrations of isoleucine, leucine, lysine, methionine, phenylalanine, threonine, and valine.

Glucose-EAA Experiment. Addition of glucose $(P<0.05)$ or EAA $(P=0.06)$ equally reduced AMPK phosphorylation by $23 \%$ (Table 1 ). Addition of both glucose and EAA reduced $(P<0.05)$ AMPK phosphorylation by $46 \%$. We observed no interaction between the glucose and EAA effects $(P=0.24)$. Addition of EAA increased $(P=0.04)$ and decreased $(P=0.03)$ mTOR $(38 \%)$ and eEF2 (12\%) phosphorylation, respectively. Moreover, EAA supplementation increased 4EBP1 phosphorylation $(P<0.01)$ by $58 \%$, regardless of glucose concentration. Glucose did not have an individual or an interactive effect with EAA on phosphorylation of mTOR, 4EBP1, or eEF2.

\section{Mammary Tissue Slices}

Acetate-EAA Experiment. Supplementation of EAA $(P=0.25)$ or acetate $(P=0.22)$ to EAA-deficient and energy substrate-deprived (without both acetate and glucose) media did not significantly affect AMPK phosphorylation but reduced it numerically by $15 \%$ (Table 2). As observed in MAC-T cells, EAA supplementation increased $(P<0.01)$ mTOR phosphorylation by $54 \%$, regardless of acetate in medium. Moreover, 4EBP1 phosphorylation $(P<0.01)$ increased 2 -fold with the addition of EAA. Unlike in MAC-T cells, EAA supplementation did not affect eEF2 phosphorylation in mammary tissue slices $(P=0.22)$. Intracellular EAA concentration increased more than 3 -fold with addition of EAA to medium, which marginally enhanced $(P=$ $0.14)$ fractional casein synthesis rates.

Glucose-EAA Experiment. Supplementation of EAA or glucose did not affect AMPK phosphorylation (Table 2). Provision of glucose numerically reduced $(P$ $=0.10)$ AMPK phosphorylation by $17 \%$, regardless of the presence or the absence of EAA in media. As in other experiments, EAA supplementation increased both mTOR $(P=0.04)$ and 4EBP1 $(P=0.01)$ phosphorylation. Supplementation of EAA or glucose did not affect eEF2 $(P=0.21)$ in mammary tissue slices. Intracellular EAA concentration in mammary tissue slices increased $(P<0.01)$ by more than 3 -fold when EAA was added to medium. Supplementation of EAA increased FSR $(P=0.02)$ by $65 \%\left(88\right.$ vs. $\left.144 \% \cdot \mathrm{h}^{-1}\right)$ irrespective of the presence or absence of glucose in media. Supplementation with glucose did not affect intracellular EAA concentrations or casein synthesis rates.

Relationships Among Signaling Proteins, FSR, and $\boldsymbol{E A A}$. When analyzed with simple linear regression models, phosphorylation of mTOR was positively and negatively associated with $4 \mathrm{EBP} 1(P=0.02)$ and eEF2 $(P=0.01)$ phosphorylation, respectively (Table 3). A 1-fold increase in mTOR phosphorylation was related to 0.81 - or -0.83 -fold changes in $4 \mathrm{EBP} 1$ and eEF2 phosphorylation, respectively. Moreover, mTOR phosphorylation explained about a quarter of the variation in phosphorylation of each $\left(\mathrm{R}^{2}=0.26\right.$ and 0.25 , 
Table 3. Regression analyses among phosphorylation states of signaling proteins (arbitrary units), total intracellular concentrations of essential AA (ICEAA, mol/L), and fractional synthesis rates of casein (FSR, $\% \cdot \mathrm{h}^{-1}$ ) in bovine mammary tissue slices ${ }^{1}$

\begin{tabular}{|c|c|c|c|c|}
\hline Independent variable ${ }^{2}$ & $\begin{array}{l}\text { Dependent } \\
\text { variable }\end{array}$ & $\begin{array}{l}\text { Regression } \\
\text { coefficient }\end{array}$ & $P$-value & Adjusted- $\mathrm{R}^{2}$ \\
\hline \multicolumn{5}{|l|}{ Simple linear regressions } \\
\hline \multirow[t]{2}{*}{ mTOR } & $4 \mathrm{EBP} 1$ & 0.81 & 0.02 & 0.26 \\
\hline & eEF2 & -0.83 & 0.01 & 0.25 \\
\hline \multirow{3}{*}{ AMPK } & mTOR & -0.52 & 0.03 & 0.16 \\
\hline & 4EBP1 & -0.59 & 0.13 & 0.06 \\
\hline & eEF2 & 0.92 & $<0.01$ & 0.40 \\
\hline \multirow[t]{4}{*}{ ICEAA } & mTOR & 0.42 & 0.01 & 0.35 \\
\hline & 4EBP1 & 0.85 & $<0.001$ & 0.51 \\
\hline & eEF2 & -0.43 & 0.01 & 0.31 \\
\hline & AMPK & -0.16 & 0.13 & 0.08 \\
\hline AMPK & FSR & -0.45 & 0.15 & 0.06 \\
\hline mTOR & FSR & 0.93 & $<0.01$ & 0.42 \\
\hline $4 \mathrm{EBP} 1$ & FSR & 0.28 & 0.03 & 0.20 \\
\hline eEF2 & FSR & -0.50 & 0.01 & 0.23 \\
\hline ICEAA & FSR & 0.24 & 0.10 & 0.11 \\
\hline \multicolumn{5}{|c|}{ Multiple linear regressions } \\
\hline ICEAA & \multirow[t]{2}{*}{ mTOR } & 0.33 & 0.04 & \multirow[t]{2}{*}{0.42} \\
\hline AMPK & & -0.39 & 0.13 & \\
\hline AMPK & \multirow[t]{3}{*}{ eEF2 } & 1.02 & 0.01 & \multirow[t]{3}{*}{0.59} \\
\hline mTOR & & -0.11 & 0.74 & \\
\hline ICEAA & & -0.21 & 0.31 & \\
\hline mTOR & \multirow[t]{2}{*}{$4 \mathrm{EBP} 1$} & 0.58 & 0.11 & \multirow[t]{2}{*}{0.38} \\
\hline ICEAA & & 0.42 & 0.09 & \\
\hline mTOR & \multirow[t]{2}{*}{ FSR } & 0.74 & 0.01 & \multirow[t]{2}{*}{0.51} \\
\hline eEF2 & & -0.33 & 0.10 & \\
\hline mTOR & \multirow{2}{*}{ FSR } & 0.80 & 0.04 & \multirow[t]{2}{*}{0.34} \\
\hline ICEAA & & 0.04 & 0.84 & \\
\hline
\end{tabular}

${ }^{1}$ When analyzed across acetate-EAA and glucose-EAA experiments.

${ }^{2} \mathrm{mTOR}=$ mammalian target of rapamycin; AMPK $=$ AMP-activated protein kinase; $4 \mathrm{EBP} 1=$ eukaryotic initiation factor $4 \mathrm{E}$ binding protein; eEF2 = eukaryotic elongation factor 2.

respectively). Phosphorylation of AMPK individually had a negative relationship with mTOR phosphorylation; a 1-fold increase in AMPK phosphorylation was associated with a 0.52 -fold decline $(P=0.03)$ in mTOR phosphorylation. A notable positive relationship $\left(\mathrm{R}^{2}=\right.$ $0.40 ; P<0.01$ ) was found between AMPK phosphorylation and eEF2 phosphorylation. Even when analyzed with mTOR phosphorylation in a multivariate regression model (Table 3), AMPK still had a strong positive $\left(P<0.01 ; \mathrm{R}^{2}=0.59\right)$ association with eEF2. A 1-fold increase in AMPK phosphorylation was associated with an almost 1-fold increase in eEF2 phosphorylation (Table 3).

Increasing intracellular EAA concentrations were positively related with increasing $\operatorname{mTOR}(P=0.01)$ or 4EBP1 $(P<0.01)$ phosphorylation but negatively associated $(P<0.01)$ with eEF2 phosphorylation. The link between intracellular EAA and mTOR phosphorylation occurred independent $(P=0.04)$ of the link between AMPK phosphorylation and mTOR phosphorylation. When analyzed together with mTOR in a multiple linear regression model, intracellular EAA tended $(P=0.09)$ to positively affect $4 \mathrm{EBP} 1$ phosphorylation independent of mTOR phosphorylation.
Phosphorylation of mTOR $(P<0.01)$ and $4 \mathrm{EBP} 1$ $(P=0.03)$ and phosphorylation of eEF2 $(P=0.01)$ were positively and negatively associated with FSR, respectively. Phosphorylation of mTOR individually explained $42 \%$ of casein synthesis rate variation. When analyzed together, both eEF2 $(P=0.10)$ and mTOR $(P=0.01)$ phosphorylation, respectively, had positive and negative relationships independently with casein synthesis rates. Intracellular EAA concentrations alone tended to be positively associated with casein synthesis rates $(P=0.10)$. However, when analyzed together with mTOR phosphorylation, the intracellular EAA effect was nullified $(P=0.84)$, whereas the mTOR effect remained significant $(P=0.04)$.

\section{DISCUSSION}

We previously demonstrated that phosphorylation of AMPK on Thr172 was negatively associated with mTOR-mediated anabolic signals in bovine mammary epithelial cells (Appuhamy et al., 2009). Burgos et al. (2013) observed a similar link between 2-deoxyglucoseinduced AMPK phosphorylation and mTOR signals that ultimately repressed global protein synthesis in 
bovine mammary epithelial cells. In the current work, addition of glucose or EAA to medium reduced $(P<$ 0.06) AMPK phosphorylation in MAC-T cells, whereas acetate did not affect it. Moreover, the decline in AMPK phosphorylation for essential AA supplementation was associated with increased ATP content in MAC-T cells. The insignificant effect of acetate supplementation on energy status of the bovine mammary epithelial cells was unexpected because acetate is known to be the most important substrate contributing to oxidative metabolism in the dairy cow mammary glands (Bickerstaffe et al., 1974). Given that the MAC$\mathrm{T}$ cells had been grown in medium with high concentrations of glucose and EAA and devoid of acetate over many passages before the experiments, MAC-T cells might prefer glucose and EAA over acetate. Although Hanigan et al. (2001) reported that the contribution of EAA to oxidative metabolism and ATP synthesis in the bovine mammary glands is relatively minor at the prevailing in vivo concentrations, concentrations of EAA in media were several-fold greater $(3.5 \mathrm{mmol} / \mathrm{L})$ than the normal plasma EAA concentrations $(\sim 0.80$ $\mathrm{mmol} / \mathrm{L}$; Rius et al., 2010) in dairy cows, and thus the contribution of EAA to oxidative metabolism may have been significant. However, neither acetate, nor glucose, nor EAA had statistically significant effects on AMPK phosphorylation, and thereby cellular energy status, but supplementation of each marginally reduced $(0.16$ $<P$-value $<0.25)$ AMPK phosphorylation by 15 to $17 \%$ in mammary tissue slices. It is possible that potentially greater nutrient concentrations in mammary tissue slices and the presence of some EAA $(0.18 \mathrm{mmol} / \mathrm{L})$ in the negative control medium may have partly masked the nutrient effects on cellular energy status in mammary tissue slices as compared with MAC-T cells.

Irrespective of the presence of acetate or glucose in the medium, supplementation of EAA significantly increased phosphorylation of mTOR at Ser2448 in MAC$\mathrm{T}$ cells and mammary tissue slices. Phosphorylation of mTOR at Ser2448 is a good biomarker of mTOR pathway activation (Chiang and Abraham, 2005). Although both glucose and EAA significantly reduced AMPK phosphorylation, only EAA significantly activated mTOR, suggesting a stronger EAA effect on mTOR that does not involve much AMPK in MAC-T cells. Consistently, intracellular concentrations of EAA (sum of isoleucine, leucine, lysine, methionine, phenylalanine, threonine, and valine concentrations) were positively related to mTOR phosphorylation $(P=0.04)$ independent of AMPK phosphorylation in mammary tissue slices. Intracellular EAA concentrations explained $35 \%$ $(P=0.01)$ of the variability in mTOR phosphorylation, whereas AMPK phosphorylation alone was negatively associated with mTOR phosphorylation $(P=0.03)$ and explained $16 \%$ of the variability.

Eukaryotic factor $4 \mathrm{E}$ binding protein 1 is a major downstream target of mTOR (Li et al., 2005). The observed positive relationship $(P=0.02)$ between mTOR phosphorylation and 4EBP1 phosphorylation agrees with this connection. Moreover, hyperphosphorylation of $4 \mathrm{EBP} 1$ enhances the initiation step of mRNA translation. Hence, the substantially increased 4EBP1 phosphorylation for EAA supplementation to MAC-T cell and tissue slice media signifies EAA-mediated positive signals on mRNA translation initiation in mammary cells. In our previous experiments, a 1-fold increase in mTOR phosphorylation was associated with a 0.89fold increase in 4EBP1 phosphorylation (Appuhamy et al., 2011). In the current work, a 1-fold increase in mTOR phosphorylation was associated with a 0.81-fold increase in 4EBP1 phosphorylation. Phosphorylation of 4EBP1 was positively associated with intracellular EAA concentration, as was its upstream kinase mTOR. However, when analyzed with mTOR phosphorylation in the same regression model, EAA still had a notable $(P=0.09)$ association with 4EBP1 phosphorylation, indicating an mTOR-independent mediation of 4EBP1 phosphorylation by EAA. Zhang and Zheng (2012) recently discovered an mTOR-independent control of 4EBP1 phosphorylation. Our finding suggests an involvement of EAA in this control. Neither acetate nor glucose had a significant effect on 4EBP1 phosphorylation in either MAC- $\mathrm{T}$ cells or mammary tissue slices. Burgos and Cant (2010) observed a significant increase in 4EBP1 phosphorylation in bovine mammary acini with the addition of a mixture of acetate and glucose to medium deprived of acetate, glucose, and all AA, including nonessential AA. However, addition of acetate and glucose did not change 4EBP1 phosphorylation in the presence of AA in their experiments. In partial agreement with these observations, addition of glucose to medium deprived of EAA numerically $(P=0.38)$ increased $4 \mathrm{EBP} 1$ phosphorylation by $18 \%$ (phosphorylation status $=1.00$ vs. 1.18 units) in MAC-T cells but the differences were not that notable when medium contained EAA (phosphorylation status $=1.75$ vs. 1.70 units). The nonessential AA present in the negative control treatments of the present experiments could presumably substitute for energy substrate by contributing to oxidative metabolism and ATP synthesis.

Eukaryotic elongation factor 2 mediates the elongation step of mRNA translation. Phosphorylation of eEF2 at Thr56 by eEF2 kinase inhibits its function. The effect of nutrient supply on phosphorylation of eEF2 at Thr56 in mammary cells has rarely been examined. Nevertheless, Christophersen et al. (2002) 
suggested that eEF2 could be a limiting factor specifically in milk protein synthesis. In the present study, as well as our previous experiments, we showed a negative association between EAA supply and phosphorylation state of eEF2, verifying that EAA not only control the initiation step of mRNA translation but also the elongation step in mammary epithelial cells. Moreover, the inverse relationship between mTOR phosphorylation and eEF2 phosphorylation is also consistent with our previous findings (Appuhamy et al., 2011, 2012). The substantially positive relationship between AMPK phosphorylation and eEF2 phosphorylation in bovine mammary cells is a distinctive finding from the present experiments. This association was independent of the relationship of eEF2 with mTOR. Horman et al. (2002) and Chan et al. (2004) reported a positive link between phosphorylation of AMPK and phosphorylation of eEF2 in heart muscle cells and liver cells, respectively. The link between AMPK and eEF2 likely occurs via eEF2 kinase because phosphorylated AMPK has been shown to directly phosphorylate, and thus activate, eEF2 kinase (Browne et al., 2004).

Provision of extracellular EAA increased casein synthesis rates of mammary tissue slices. When analyzed across both experiments, intracellular EAA concentrations were positively $(P=0.10)$ related to casein synthesis rates in a simple linear regression model. A greater proportion of this link appeared to occur via mTOR as the relationship was negated $(P=0.84)$ when mTOR phosphorylation was included in the model. Although eEF2 phosphorylation was associated with mTOR phosphorylation, it tended $(P=0.10)$ to have a negative effect on casein synthesis rates, independent of mTOR phosphorylation. Nonetheless, mTOR phosphorylation was more strongly connected to casein synthesis rates than to eEF2 phosphorylation. A 1-fold increase in mTOR phosphorylation was independently associated with a $0.74 \% \cdot \mathrm{h}^{-1}(P=0.01)$ fractional casein synthesis rate increase, whereas a 1 -fold increase in eEF2 phosphorylation was related to a $0.33 \% \cdot \mathrm{h}^{-1}(P=$ $0.10)$ decline in casein synthesis rates.

In parallel with cell signaling, the effects of extracellular acetate or glucose provisions on casein synthesis rates were minimal. Effects of acetate supply on milk protein synthesis are quite inconsistent across in vivo studies in the literature. Continuous intraruminal infusion of acetate in dairy cows (Rook and Balch, 1961) and dairy goats (Lough et al., 1983) have been reported to increase milk fat yields, without any effect on protein yield, whereas in Safayi and Nielsen (2013), provision of acetate increased milk protein yield particularly in early-lactating cows but did not affect it in cows in late lactation. Increasing milk protein responses for acetate infusions in Safayi and Nielsen (2013) were associated with increasing negative $\mathrm{N}$ balance in dairy cows. We did not see such an effect of cellular $\mathrm{N}$ balance on acetate responses. Supplementation of acetate to medium deprived of EAA, acetate, and glucose did not change casein synthesis rates, but addition of EAA alone increased it by $55 \%$. Addition of both acetate and EAA did not affect casein synthesis rates. Purdie et al. (2008) reported a $12 \%$ increase in milk protein yield in response to AA infusion and no change in milk protein yield when AA was infused with acetate. Provision of glucose with or without EAA in the medium did not affect casein synthesis rates in mammary tissue slices. In contrast to our results, Toerien et al. (2010) demonstrated that jugular infusion of glucose alone or with EAA increased milk protein yield in dairy cows. Moreover, abomasal infusion of starch increased protein yield in dairy cows regardless of the infusion of casein (Rius et al., 2010). Nonetheless, in vivo glucose effects can occur through many mechanisms that cannot be perfectly tested with in vitro systems. For example, additional glucose can spare AA from utilization in liver gluconeogenesis and thereby more AA can be delivered to the mammary glands. Moreover, elevated plasma glucose concentrations stimulate secretion of insulin, which in turn enhances AA uptake and protein synthesis by the mammary gland (Al-Trad et al., 2009; Burgos and Cant, 2010; Appuhamy et al., 2011).

\section{CONCLUSIONS}

In summary, AMPK phosphorylation is positively responsive to decreasing ATP content in bovine mammary epithelial cells. Besides glucose, EAA can serve as an important energy substrate to mammary cells when supplied in high concentrations. Although phosphorylation of AMPK inversely affected mTOR signals, the stimulatory effects of EAA on mTOR signals were significantly stronger than the inverse effects of AMPK. Phosphorylated, and thus activated, mTOR considerably enhanced casein synthesis rates by phosphorylating 4EBP1, which is rate limiting to the initiation of protein synthesis. On the other hand, phosphorylated, and thus activated, AMPK had a positive association with phosphorylation of eEF2, which is detrimental to protein synthesis. However, the positive effect of mTOR phosphorylation on protein synthesis rates was significantly stronger than the negative effect of eEF2 phosphorylation. Overall, EAA strongly enhanced milk protein synthesis by signaling via mTOR pathway independent of AMPK, which was responsive to cellular energy status but had a marginal effect on milk protein synthesis rates. 


\section{ACKNOWLEDGMENTS}

The guidance of C. Parsons (Department of Dairy Science, Virginia Tech, Blacksburg) in cell staining is greatly appreciated. This work was partially funded by the Virginia State Dairymen's Association (Bridgewater, VA), Land O'Lakes/Purina Feed LLC (Arden Hills, MN), the Cooperative State Research, Education and Extension Service, US Department of Agriculture (Beltsville, MD), under Project No. NC-1040, and the College of Agriculture and Life Sciences of Virginia Tech.

\section{REFERENCES}

Al-Trad, B., K. Reisberg, T. Wittek, G. B. Penner, A. Alkaassem, G. Gäbel, M. Fürll, and J. R. Aschenbach. 2009. Increasing intravenous infusions of glucose improve body condition but not lactation performance in midlactation dairy cows. J. Dairy Sci. 92:5645-5658.

Appuhamy, J. A., A. L. Bell, W. A. Nayananjalie, J. Escobar, and M. D. Hanigan. 2011. Essential amino acids regulate both initiation and elongation of mRNA translation independent of insulin in MAC-T cells and bovine mammary tissue slices. J. Nutr. 141:1209-1215.

Appuhamy, J. A., N. A. Knoebel, W. A. Nayananjalie, J. Escobar, and M. D. Hanigan. 2012. Isoleucine and leucine independently regulate mTOR signaling and protein synthesis in MAC-T cells and bovine mammary tissue slices. J. Nutr. 142:484-491.

Appuhamy, J. A. D. R. N., C. Bray, J. Escobar, and M. D. Hanigan. 2009. Effects of acetate and essential amino acids on protein synthesis signaling in bovine mammary epithelial cells in vitro. J. Dairy Sci. 92(E-Suppl. 1):44. (Abstr.)

Bauman, D. E., D. L. Ingle, R. W. Mellenberger, and C. L. Davis. 1973. Factors affecting in vitro lipogenesis by bovine mammary tissue slices. J. Dairy Sci. 56:1520-1525.

Bequette, B. J., F. R. Backwell, C. E. Kyle, A. G. Calder, V. Buchan, L. A. Crompton, J. France, and J. C. Macrae. 1999. Vascular sources of phenylalanine, tyrosine, lysine, and methionine for casein synthesis in lactating goats. J. Dairy Sci. 82:362-377.

Bequette, B. J., C. E. Kyle, L. A. Crompton, S. E. Anderson, and M. D. Hanigan. 2002. Protein metabolism in lactating goats subjected to the insulin clamp. J. Dairy Sci. 85:1546-1555.

Bernocchi, P., C. Ceconi, A. Cargnoni, P. Pedersini, S. Curello, and R. Ferrari. 1994. Extraction and assay of creatine phosphate, purine, and pyridine nucleotides in cardiac tissue by reversed-phase highperformance liquid chromatography. Anal. Biochem. 222:374-379.

Bickerstaffe, R., E. F. Annison, and J. L. Linzell. 1974. The metabolism of glucose, acetate, lipids and amino acids in lactating dairy cows. J. Agric. Sci. 82:71-85.

Bolster, D. R., S. J. Crozier, S. R. Kimball, and L. S. Jefferson. 2002. AMP-activated protein kinase suppresses protein synthesis in rat skeletal muscle through down-regulated mammalian target of rapamycin (mTOR) signaling. J. Biol. Chem. 277:23977-23980.

Browne, G. J., S. G. Finn, and C. G. Proud. 2004. Stimulation of the AMP-activated protein kinase leads to activation of eukaryotic elongation factor 2 kinase and to its phosphorylation at a novel site, serine 398. J. Biol. Chem. 279:12220-12231.

Burgos, S. A., and J. P. Cant. 2010. IGF-1 stimulates protein synthesis by enhanced signaling through mTORC1 in bovine mammary epithelial cells. Domest. Anim. Endocrinol. 38:211-221.

Burgos, S. A., J. J. Kim, M. Dai, and J. P. Cant. 2013. Energy depletion of bovine mammary epithelial cells activates AMPK and suppresses protein synthesis through inhibition of mTORC1 signaling. Horm. Metab. Res. 45:183-189. http://dx.doi. org/10.1055/s-0032-1323742.
Chan, A. Y., C. L. Soltys, M. E. Young, C. G. Proud, and J. R. Dyck. 2004. Activation of AMP-activated protein kinase inhibits protein synthesis associated with hypertrophy in the cardiac myocyte. J. Biol. Chem. 279:32771-32779.

Chiang, G. G., and R. T. Abraham. 2005. Phosphorylation of mammalian target of rapamycin (mTOR) at Ser-2448 is mediated by p70S6 kinase. J. Biol. Chem. 280:25485-25490.

Christophersen, C. T., J. Karlsen, M. O. Nielsen, and B. Riis. 2002. Eukaryotic elongation factor-2 (eEF-2) activity in bovine mammary tissue in relation to milk protein synthesis. J. Dairy Res. 69:205-212.

Daniels, K. M., M. L. McGilliard, M. J. Meyer, M. E. Van Amburgh, A. V. Capuco, and R. M. Akers. 2009. Effects of body weight and nutrition on histological mammary development in Holstein heifers. J. Dairy Sci. 92:499-505.

Deshmukh, A. S., J. T. Treebak, Y. C. Long, B. Viollet, J. F. Wojtaszewski, and J. R. Zierath. 2008. Role of adenosine $5^{\prime}$-monophosphateactivated protein kinase subunits in skeletal muscle mammalian target of rapamycin signaling. Mol. Endocrinol. 22:1105-1112.

Dimenna, G. P., and R. S. Emery. 1980. Factors affecting fatty acid oxidation in bovine mammary tissue. Lipids 15:497-503.

Escobar, J., J. W. Frank, A. Suryawan, H. V. Nguyen, S. R. Kimball, L. S. Jefferson, and T. A. Davis. 2006. Regulation of cardiac and skeletal muscle protein synthesis by individual branched-chain amino acids in neonatal pigs. Am. J. Physiol. Endocrinol. Metab. 290:E612-E621.

FASS (Federation of Animal Science Societies). 2010. Guide for the Care and Use of Agricultural Animals in Research and Teaching. 3rd ed. FASS, Champaign, IL.

Hanigan, M. D., and R. L. Baldwin. 1994. A mechanistic model of mammary gland metabolism in the lactating cow. Agric. Syst. 45:369-419.

Hanigan, M. D., J. P. Cant, D. C. Weakley, and J. L. Beckett. 1998. An evaluation of postabsorptive protein and amino acid metabolism in the lactating dairy cow. J. Dairy Sci. 81:3385-3401.

Hanigan, M. D., L. A. Crompton, J. A. Metcalf, and J. France. 2001. Modelling mammary metabolism in the dairy cow to predict milk constituent yield, with emphasis on amino acid metabolism and milk protein production: Model construction. J. Theor. Biol 213:223-239.

Horman, S., G. Browne, U. Krause, J. Patel, D. Vertommen, L. Bertrand, A. Lavoinne, L. Hue, C. Proud, and M. Rider. 2002. Activation of AMP-activated protein kinase leads to the phosphorylation of elongation factor 2 and an inhibition of protein synthesis. Curr. Biol. 12:1419-1423.

Huhtanen, P., and A. N. Hristov. 2009. A meta-analysis of the effects of dietary protein concentration and degradability on milk protein yield and milk $\mathrm{N}$ efficiency in dairy cows. J. Dairy Sci. 92:3222-3232.

Huynh, H. T., G. Robitaille, and J. D. Turner. 1991. Establishment of bovine mammary epithelial cells (MAC-T): An in vitro model for bovine lactation. Exp. Cell Res. 197:191-199.

Jeyapalan, A. S., R. A. Orellana, A. Suryawan, P. M. O'Connor, H. V. Nguyen, J. Escobar, J. W. Frank, and T. A. Davis. 2007. Glucose stimulates protein synthesis in skeletal muscle of neonatal pigs through an AMPK- and mTOR-independent process. Am. J. Physiol. Endocrinol. Metab. 293:E595-E603.

Kimball, S. R., and L. S. Jefferson. 2006. Signaling pathways and molecular mechanisms through which branched-chain amino acids mediate translational control of protein synthesis. J. Nutr. 136:227S-231S

Kudchodkar, S. B., G. Q. Del Prete, T. G. Maguire, and J. C. Alwine. 2007. AMPK-mediated inhibition of mTOR kinase is circumvented during immediate-early times of human cytomegalovirus infection. J. Virol. 81:3649-3651.

Li, X., I. Alafuzoff, H. Soininen, B. Winblad, and J. J. Pei. 2005. Levels of mTOR and its downstream targets 4E-BP1, eEF2, and eEF2 kinase in relationships with tau in Alzheimer's disease brain. FEBS J. 272:4211-4220. 
Lobley, G. E. 1990. Energy metabolism reactions in ruminant muscle: Responses to age, nutrition, and hormonal status. Reprod. Nutr. Dev. 30:13-34.

Lough, D. S., E. C. Prigge, W. H. Hoover, and G. A. Varga. 1983. Utilization of ruminally infused acetate or propionate and abomasally infused casein by lactating goats. J. Dairy Sci. 66:756-762.

Manfredi, G., L. Yang, C. D. Gajewski, and M. Mattiazzi. 2002. Measurements of ATP in mammalian cells. Methods 26:317-326.

Mukherjee, P., T. J. Mulrooney, J. Marsh, D. Blair, T. C. Chiles, and T. N. Seyfried. 2008. Differential effects of energy stress on AMPK phosphorylation and apoptosis in experimental brain tumor and normal brain. Mol. Cancer 7:37.

O'Quinn, P. R., D. A. Knabe, and G. Wu. 2002. Arginine catabolism in lactating porcine mammary tissue. J. Anim. Sci. 80:467-474.

Purdie, N. G., D. R. Trout, D. P. Poppi, and J. P. Cant. 2008. Milk synthetic response of the bovine mammary gland to an increase in the local concentration of amino acids and acetate. J. Dairy Sci. 91:218-228.

Rius, A. G., J. A. D. R. N. Appuhamy, J. Cyriac, D. Kirovski, O. Becvar, J. Escobar, M. L. McGilliard, B. J. Bequette, R. M. Akers, and M. D. Hanigan. 2010. Regulation of protein synthesis in mammary glands of lactating dairy cows by starch and amino acids. J. Dairy Sci. 93:3114-3127.
Rook, J. A., and C. C. Balch. 1961. The effects of intraruminal infusions of acetic, propionic and butyric acids on the yield and composition of the milk of the cow. Br. J. Nutr. 15:361-369.

Safayi, S., and M. O. Nielsen. 2013. Intravenous supplementation of acetate, glucose or essential amino acids to an energy and protein deficient diet in lactating dairy goats: Effects on milk production and mammary nutrient extraction. Small Rumin. Res. 112:162173.

Toerien, C. A., D. R. Trout, and J. P. Cant. 2010. Nutritional stimulation of milk protein yield of cows is associated with changes in phosphorylation of mammary eukaryotic initiation factor 2 and ribosomal S6 kinase 1. J. Nutr. 140:285-292.

Williams, J. H., S. E. Vidt, and J. Rinehart. 2008. Measurement of sarcoplasmic reticulum $\mathrm{Ca}^{2+}$ ATPase activity using high-performance liquid chromatography. Anal. Biochem. 372:135-139.

Zhang, Y., and X. F. Zheng. 2012. mTOR-independent 4EBP1 phosphorylation is associated with cancer resistance to mTOR kinase inhibitors. Cell Cycle 11:594-603. 